\title{
Editorial
}

\section{Following the Rules}

\author{
Markus K. Heinemann ${ }^{1}$ \\ ${ }^{1}$ Department of Cardiac, Thoracic and Vascular Surgery, \\ Universitaetsmedizin Mainz, Mainz, Germany
}

Thorac Cardiovasc Surg 2018;66:523-524.

Abstract

Now what's all this?

Instructions for Authors are meant to be the general guidelines on how to compile a manuscript for a certain journal. Many items are identical or similar between journals, others are not. Publishing remains an individual task which, in turn, makes the scene of scientific literature refreshingly diverse. With a changing environment and further development of techniques and facilities, it is one of the Editor's numerous tasks to update these instructions every now and then. For The Thoracic and Cardiovascular Surgeon and its open access sister journal The Thoracic and Cardiovascular Surgeon Reports, this time has come.

In the new version, authors will find more detailed information on requirements for figures and tables as well as video submissions and more. Adherence to technical regulations should avoid prompt unsubmission for formal reasons, something we unfortunately still see far too often. Authors must bear in mind that these instructions were not written to make their life more miserable but with the optimistic basic composure that the manuscript will be accepted and then undergo the publisher's production process-which is where most of the purely technical prerequisites do come from.

In addition there are the basic conditions for a scientific manuscript as such which one would think should be matters of course. Unfortunately they are not. ${ }^{1}$ Although we are a relatively small journal with a select and close author- and readership, we still see cases of fraud every year. For big journals with a high reputation and lots of submissions this is even more of a problem, resulting in a constant number of retractions, which in turn damages their renown. ${ }^{2}$ The scientific community has developed a series of requirements, let us call them "moral instructions," the adherence to which should in fact guarantee that the published material is true and was acquired under decent circumstances.

The International Committee of Medical Science Editors (ICMJE) ${ }^{3}$ constantly updates its recommendations deliberating on such seemingly trivial subjects like who should be called an author (and, perhaps more important, who should not). (c) 2018 Georg Thieme Verlag KG Stuttgart · New York
DOI https://doi.org/ 10.1055/s-0038-1673411. ISSN 0171-6425. 
The ICMJE has also published a very explicit Conflict of Interest declaration form which was gladly accepted by many journals including this one. ${ }^{4}$

The Committee on Publication Ethics (COPE) is a valuable source mainly for editors and publishers to resort to in case of doubt about ethical integrity. ${ }^{5}$ Authors are well advised to be familiar with these best practice consensus statements.

The CONSORT Statement (Consolidated Standards of Reporting Trials) ${ }^{6}$ is required by many journals for manuscripts reporting randomized clinical trials. For authors, it provides a flow diagram and a helpful checklist to be submitted together with the manuscript.

For observational studies, more common in the surgical community, there is a similar helpline: STROBE Statement (Strengthening the Reporting of Observational Studies in Epidemiology), ${ }^{7,8}$ again providing useful checklists tailored to the type of study (to be) done.

In the field of secondary sources, such as systematic reviews and the overly popular meta-analyses, there is the PRISMA Statement (Preferred Reporting Items for Systematic Reviews and Meta-Analyses), ${ }^{9}$ complete with checklist and flow diagram for manuscript submission.

Animal rights are a big issue with the cardiothoracic surgical community because the evaluation of new operative techniques and medical devices often requires testing in large animal models. The standards universally agreed upon can be found in the ARRIVE guidelines (Animal Research: Reporting of In Vivo Experiments). ${ }^{10}$ Local regulations may apply in addition. There are detailed ones issued by the European Union ${ }^{11}$ and the United States of America. ${ }^{12}$

A very helpful organization offering access to all these and other useful Websites as well as providing excellent guidance for the conscientious scientist is the Equator Network (Enhancing the QUAlity and Transparency of health Research). ${ }^{13}$

The Declaration of Helsinki, as developed by the World Medical Association (WMA), defines the fundamental "ethical principles for medical research involving human subjects including research on identifiable human material and data." ${ }^{14}$ One cannot repeat often enough its simple point of origin "the health of my patient will be my first consideration."

Data retention: Authors must be prepared to provide the original research data, on which their manuscript is based, to the Editor. These data must be retained for several years in case there are doubts about reproducibility or, worse, the suspicion of manipulation or fabrication. Many journals are introducing mandatory open data sharing, especially in the basic sciences.

Originality: The same research should not be published in more than one journal. Multiple, redundant, or concurrent submission or even publication is considered unacceptable unethical behavior and will be reported if detected.

Bearing in mind that Instructions for Authors are to facilitate the writing process we have now compiled the relevant standards in one source: this Editorial. It is linked directly from the Instructions. All authors should thereby be aware of and agree to the statements made in the Abstract above. The number of forms to be filled in and submitted for each manuscript, independent of the type of research done, has consequently been kept to a minimum: (1) the declaration of any or no conflict of interest, according to the ICMJE, ${ }^{4}$ and (2) our very own Conditions for Publication form which needs to be manually signed (for a good reason) by each individual listed as an author. Where required, IRB (Institutional Review Board) approval must, of course, be individually stated in the Methods section.

One may still brazenly lie, of course, but to do so in public in detail and in writing should have a comparatively high inhibition threshold. With technology for fraud detection being constantly updated and utilized routinely, also by this journal, the chances of being found out are very, very likely. And the higher one tried to rise, the deeper one is bound to fall-and rightly so.

\section{References}

1 Lüscher TF. The codex of science: honesty, precision, and truthand its violations. Eur Heart J 2013;34(14):1018-1023

2 Fang FC, Casadevall A. Retracted science and the retraction index. Infect Immun 2011;79(10):3855-3859

3 International Committee of Medical Science Editors: Recommendations. Available from: http://www.icmje.org/recommendations/; accessed September 182018

4 International Committee of Medical Science Editors: Conflicts of Intrest. Available from: http://www.icmje.org/conflicts-of-interest/; accessed September 182018

5 Latest from Committee on Publication Ethics. Available from: https://publicationethics.org/; accessed September 182018

6 Consolidated Standards of Reporting Trials. Available from: http://www.consort-statement.org; accessed September 182018

7 Strengthening the Reporting of Observational Studies in Epidemiology Statement. Available from: https://www.strobe-statement.org/ index.php?id=strobe-home; accessed September 182018

8 von Elm E, Altman DG, Egger M, Pocock SJ, Gøtzsche PC, Vandenbroucke JP; STROBE Initiative. Strengthening the Reporting of Observational Studies in Epidemiology (STROBE) statement: guidelines for reporting observational studies. BMJ 2007;335 (7624):806-808

9 Preferred Reporting Items for Systematic Reviews and MetaAnalyses Statement. Available from: http://www.prisma-statement.org/; accessed September 182018

10 Animal Research: Reporting of In Vivo Experiments Guidelines. Available from: https://www.nc3rs.org.uk/arrive-guidelines; accessed September 182018

11 Legislation for the protection of animals used for scientific purposes. European Commission. Available from: http://ec.europa.eu/ environment/chemicals/lab_animals/legislation_en.htm; accessed September 182018

12 U.S. Department of Health and Human Services, National Institutes of Health. Public health service policy on human care and use of laboratory animals. Available from: https://grants.nih.gov/grants/ olaw/references/phspolicylabanimals.pdf; accessed September 18 2018

13 Enhancing the Quality and Transparency of Health Research Network. Available from: http://www.equator-network.org/; accessed September 182018

14 World Medical Association Declaration of Helsinki. Ethical principles for medical research involving human subjects. Available from: https://www.wma.net/policies-post/wma-declaration-of-helsinkiethical-principles-for-medical-research-involving-human-subjects/; accessed September 182018 